\title{
Anti-citrullinated peptide autoantibodies, human leukocyte antigen shared epitope and risk of future rheumatoid arthritis: a nested case-control study
}

\author{
Elizabeth V Arkema ${ }^{1,2^{*}}$, Barbara L Goldstein ${ }^{1}$, William Robinson ${ }^{3}$, Jeremy Sokolove ${ }^{3}$, Catriona A Wagner ${ }^{3}$,
} Susan Malspeis ${ }^{1}$, Bernard Rosner ${ }^{2,4}$, Francine Grodstein ${ }^{2,5}$, Elizabeth W Karlson ${ }^{1}$ and Karen H Costenbader ${ }^{1}$

\begin{abstract}
Introduction: The aim of this study was to characterize anti-citrullinated peptide antibody (ACPA) serostatus in pre-clinical rheumatoid arthritis (RA) with and without Human Leukocyte Antigen-Shared Epitope (HLA-SE) alleles.

Methods: We identified 192 women in the Nurses' Health Study cohorts with blood samples obtained 4 months to 17 years prior to medical record-confirmed RA diagnosis. Three controls were selected matched on age, cohort, menopausal status and post-menopausal hormone use. Reactivities to 18 ACPAs were measured using a custom BioPlex platform. We used conditional logistic regression to calculate the relative risk (RR) of RA for any ACPA-positive and peptide-specific ACPA-positive and examined RRs by time between blood draw and RA onset. Measures of multiplicative and additive interaction between any ACPA-positive and HLA-SE were calculated.

Results: All ACPAs by peptide groups were significantly associated with RA risk, RRs ranged from 4.7 to 11.7. The association between ACPA and RA varied over time with the strongest association in those with blood draw less than 5 years before onset (RR 17.0 [95\% Cl 5.8 to 53.7]) and no association 10 or more years prior to onset (RR 1.4 [95\% Cl 0.5 to 4.3]). Individuals with both HLA-SE and any ACPA-positive had the highest risk of RA. HLA-SE-positive RA cases showed reactivity to more ACPA types than HLA-SE negative ( $X^{2}$ test for trend, $P=0.01$ ).

Conclusions: There is increasing ACPA reactivity up to 10 years before RA onset with the strongest association within 5 years of RA onset. The magnitude of the response to ACPAs, in combination with the presence of HLA-SE, is most important for identifying those individuals with the highest risk of RA.
\end{abstract}

\section{Introduction}

Rheumatoid arthritis (RA) is an autoimmune inflammatory arthropathy characterized by inflammation and autoantibodies directed against citrullinated peptides. The anticyclic citrullinated peptide (anti-CCP) test, a commercial assay that relies upon reactivity to several modified or synthetic CCPs, is a useful assay for diagnosing RA and is highly specific for RA [1]. Recently, research has focused

\footnotetext{
* Correspondence: earkema@post.harvard.edu

'Division of Rheumatology, Immunology and Allergy, Department of Medicine, Brigham and Women's Hospital, Harvard Medical School, 75 Francis Street, Boston, MA 02115, USA

${ }^{2}$ Department of Epidemiology, Harvard School of Public Health, 677 Huntington Avenue, Boston, MA 02115, USA

Full list of author information is available at the end of the article
}

on autoantibodies directed against specific proteins and/or peptides found in the synovium, such as vimentin, fibrinogen and enolase [2-7], in an effort to identify a specific antigen responsible for inciting RA. Patients with RA may be positive for more than one anticitrullinated peptide antibody (ACPA), and there appears to be epitope spreading of ACPA reactivity in the years leading up to diagnosis [5,6,8-10].

Human leukocyte antigen (HLA)-DRB1 shared epitope $(H L A-S E)$ alleles are the strongest genetic risk factors for RA, carrying a two- to threefold increased risk [11-13]. Past case-control studies have found that having both HLA-SE and anti-CCP antibodies confers a greater risk of developing RA than either one alone [14-16]. Among 
individuals with RA, those with $H L A-S E$ alleles are more likely to have anti-CCP antibodies [2,4,17-21].

Most studies of individual ACPAs and RA risk have included patients with early or well-established RA, and those that have included pre-RA patients have not examined the combined effect of ACPA and HLA-SE. Our objective in the present study was to characterize reactivity to ACPAs targeted to epitopes found in the rheumatoid synovium in the preclinical period before RA onset using a nested case-control design within the Nurses' Health Study (NHS) and Nurses' Health Study II (NHSII) cohorts. We examined the relationship between the number of ACPAs recognized and the time interval until RA symptom onset. Furthermore, we aimed to understand the interaction between ACPA and HLA-SE in determining RA risk within this preclinical window.

\section{Methods}

\section{Study design and population}

The NHS is a prospective cohort of 121,700 female nurses ages 30 to 55 years living in 11 states in 1976. The NHSII is a similar cohort started in 1989 of 116,430 female nurses ages 25 to 42 years living in 14 states in the United States. The NHS and NHSII participants completed questionnaires at baseline and every 2 years afterward regarding diseases, lifestyle and health practices. From 1989 to 1990, 32,826 NHS participants (27\%) provided blood samples, and from 1996 and 1999, 29,611 NHSII participants (25\%) provided blood samples for future studies. We excluded women with any history of cancer (except nonmelanoma skin cancer) at the time of blood draw. All aspects of this study were approved by the Partners' HealthCare System's institutional review board. The participants' return of a completed questionnaire was accepted as informed consent and was approved by the review board.

\section{Identification of rheumatoid arthritis cases}

Methods of RA case identification and validation have been described in detail in past publications $[22,23]$. Briefly, nurses who self-reported a doctor-diagnosed connective tissue disease underwent a screening questionnaire for symptoms using the Connective Tissue Diseases Screening Questionnaire [24]. If the result was positive, a detailed medical record review was performed to determine definite RA using the American College of Rheumatology (ACR) classification criteria [25]. Individuals who met four of seven of the ACR criteria documented in the medical record were defined as cases. There were a small number of cases included as incident RA with only three of the ACR criteria and a physician's diagnosis, but further agreed upon by two rheumatologists on the basis of chart review $(n=8)$. There were 11 cases with a missing date of symptom onset; in those cases, we therefore imputed the time of onset by assuming that the time between onset and diagnosis was similar to those in the rest of the cases (median time between onset and diagnosis was 6 months). Only cases with a blood draw at least 3 months before symptom onset were included.

\section{Identification of matched controls}

Three controls for each confirmed incident RA case were randomly chosen from among participants with stored blood, matched on age ( \pm 1 year), menopausal status and postmenopausal hormone use, as well as on time of data collection and fasting status at blood draw. In NHSII, premenopausal women were also matched on timing of blood sample in the menstrual cycle. We excluded from the control group any self-reported RA not confirmed by a doctor and any participants who reported other connective tissue diseases.

\section{Laboratory methods}

\section{Anticitrullinated peptide antibodies}

Potential RA-associated antigens identified from the literature and through proteomic screening [26] were coupled to spectrally distinct beads using the BioPlex multiplex assay platform (Bio-Rad Laboratories, Hercules, CA, USA) for analysis and a Luminex 200 instrument (Luminex, Austin, TX, USA) as previously described [6]. Three preestablished control serum samples consisting of high reactivity, low reactivity and no reactivity were run on each plate as internal controls: negative, low positive and high positive. Reactivities to 18 ACPAs targeted to synovial epitopes were measured in raw fluorescent intensity units and determined to be positive if they were more than three times the standard deviation above the mean in controls. A less conservative cutoff of more than two times the standard deviation was used in sensitivity analysis. ACPA targets included citrullinated enolase, biglycan, clusterin, fibrinogen, histone $2 \mathrm{~A}$, histone $2 \mathrm{~B}$ and vimentin. Three native peptides were also assayed to serve as controls (fibrinogen, histone $2 \mathrm{~B}$ and vimentin). A detailed list of each ACPA target can be found in Additional file 1: Table S1. Intrabatch coefficients of variation $(\mathrm{CVs})$ were $4 \%$ to $10 \%$, and interbatch CVs were $6 \%$ to $16 \%$. We examined reactivity to any ACPA overall, ACPAs by peptide group (for example, reactivity to any citrullinated clusterin peptide) and individual ACPAs. A count of ACPAs was carried out by adding the number of positive ACPAs. An anti-CCP second-generation assay was performed by bead-based microarray using beads coated with peptide antigen (generously provided by Bio-Rad Laboratories). A relative fluorescence value greater than 1,500 was considered anti-CCP-positive, as this cutoff was determined to have similar sensitivity and specificity to a variety of platebased, anti-CCP2 enzyme-linked immunosorbent assays. 


\section{HLA-SE}

HLA low to intermediate typing was performed by One Lambda LABType reverse SSO Luminex DNA typing method (One Lambda, Canoga Park, CA, USA). First, target DNA was PCR-amplified using biotinylated groupspecific primers. The PCR product was then denatured and hybridized to sequence-specific oligonucleotide probes bound to fluorescently coded microspheres to identify alleles encoded by the sample DNA. A flow analyzer, the Luminex 200, identified fluorescence intensity of R-phycoerythrin-conjugated streptavidin on each microsphere. The assignment of the HLA typing was based on the reaction pattern compared to probe specificities associated with published HLA gene sequences. HLA high-resolution typing was performed by sequencing. HLA locus-specific amplification was performed in a thermal cycler using the amplification primer mix and template DNA. Sequencing was performed using BigDye Terminator sequencing chemistry (Applied Biosystems, Foster City, CA, USA). Group-specific sequencing primers were used when necessary to resolve allelespecific ambiguities. We defined $H L A-S E$-positive as those having at least one SE allele (HLA-DRB*0401, 0404, 0405, 0408, 0101, 0102, 1001 or 09). HLA-SE data were available for 190 cases and 283 controls from another study. The distribution of demographics and potential confounders in this subset with HLA-SE data was similar to that of the full study population.

\section{Statistical analysis}

Covariates were collected from the questionnaire before blood draw and were selected for analysis if associated with RA. Continuous variables included were pack-years of smoking, measured by the product of years of smoking and packs of cigarettes per day [27-29]; cumulative average alcohol intake in grams per day $[28,30]$; and body mass index (BMI) in kilograms per square meter [31]. Less than $1 \%$ of study participants had missing data for each continuous covariate; therefore, median values from the control group were imputed. Irregular menses [22] was included as a dichotomous variable, and an indicator was used for missing data.

Risk ratios (RRs) and their 95\% confidence intervals (95\% CIs) were obtained from conditional logistic regression models. Multivariable models included age at blood draw, pack-years of smoking, BMI, alcohol intake and irregular menses. Multivariable Cox proportional hazards models, including an interaction term for each ACPA and time from blood draw to symptom onset, were used to examine whether the association between each ACPA and RA varied over time. Preclinical RA cases were stratified into subgroups based on time between blood draw and onset of RA. Because each participant donated a single blood sample, the subgroups were mutually exclusive.
Effect modification of the association between ACPA positivity and RA by HLA-SE was assessed using unconditional logistic regression with adjustment for matching factors. The ratio of odds ratios was calculated to examine the multiplicative interaction between ACPA and HLA-SE, and additive interaction was assessed by calculating the synergy index (S) [32]. A $X^{2}$ test for trend was used to compare categorical ACPA count over time intervals. To determine if $H L A-S E$ was associated with peptide-specific ACPAs, we used logistic regression models.

\section{Results}

We included 192 cases and 567 controls in the study (8 matched sets had fewer than 3 controls). On average, compared to controls, cases were more likely to have ever smoked cigarettes and drank less alcohol prior to blood draw (Table 1). Cases had a mean age of 59.9 years at

Table 1 Characteristics of preclinical rheumatoid arthritis cases and matched controls at time of blood collection in the Nurses' Health Study and Nurses' Health Study II $^{\text {a }}$

\begin{tabular}{|c|c|c|}
\hline Characteristics & $\begin{array}{l}\text { RA cases } \\
(N=192)\end{array}$ & $\begin{array}{l}\text { Matched cc } \\
(N=567)\end{array}$ \\
\hline \multicolumn{3}{|l|}{ Cohort, $n(\%)$} \\
\hline NHS & $136(70.8)$ & $405(71.4)$ \\
\hline NHSII & $56(29.2)$ & $162(28.6)$ \\
\hline Caucasian, $n(\%)$ & $190(99.0)$ & $556(98.1)$ \\
\hline Mean age at blood collection, years (SD) & $52.3(8.0)$ & $52.4(8.1)$ \\
\hline Never smoker, $n$ (\%) & $83(43.2)$ & $279(49.2)$ \\
\hline Current smoker, $n(\%)$ & $33(17.2)$ & $82(14.5)$ \\
\hline Past smoker, $n(\%)$ & $76(39.6)$ & $206(36.3)$ \\
\hline Mean pack-years of smoking ${ }^{\mathrm{b}}$ (SD) & $23.1(16.4)$ & $20.8(18.8)$ \\
\hline Mean alcohol intake, g/day (SD) & $4.2(5.6)$ & $5.7(8.9)$ \\
\hline Mean BMI, kg/m² (SD) & $26.1(5.0)$ & $25.0(4.4)$ \\
\hline Premenopausal, $n(\%)$ & $65(33.9)$ & $193(34.0)$ \\
\hline Parous, $n(\%)$ & $175(91.1)$ & $511(90.1)$ \\
\hline Irregular menses, $n(\%)$ & $32(16.7)$ & $56(9.9)$ \\
\hline Positive for any ACPA, $n(\%)$ & $48(25.0)$ & $38(6.7)$ \\
\hline Positive for anti-CCP, $n(\%)$ & $23(12.0)$ & $0(0)$ \\
\hline Mean age at RA diagnosis, years (SD) & $59.9(9.9)$ & \\
\hline Mean time to RA onset, months (SD) & $91.1(53.6)$ & \\
\hline Median time to RA onset, months (IQR) & $87.5(92.0)$ & \\
\hline Morning stiffness, $n(\%)$ & $143(74.5)$ & \\
\hline Arthritis three or more joint areas, $n(\%)$ & $176(91.7)$ & \\
\hline Hand arthritis, $n$ (\%) & $191(99.5)$ & \\
\hline Symmetric arthritis, $n$ (\%) & $188(97.9)$ & \\
\hline Nodules, $n(\%)$ & $21(10.9)$ & \\
\hline Erosions, $n(\%)$ & $43(22.4)$ & \\
\hline
\end{tabular}

${ }^{\mathrm{a} A C P A}$ : anticitrullinated peptide autoantibody, BMI: body mass index, CCP: cyclic citrullinated peptide, NHS: Nurses' Health Study, NHSII: Nurses' Health




diagnosis, and the median time between blood draw and diagnosis was 7.3 years (range: 4 months to 17.3 years). At the time of blood draw, $25.0 \%$ of cases and $6.7 \%$ of controls were positive for at least one ACPA (Table 1).

The RR associated with any ACPA-positive was 4.9 (95\% $\mathrm{CI}=2.9$ to $8.2 ; P<0.0001)$. Each ACPA within each peptide type was significantly associated with risk of RA. RRs ranged from 4.7 to 11.7 (Table 2). All individual ACPAs were associated with RA, except for fibrinogen A 211-230 citrullinated cyclic (Additional file 1: Table S1).

Relationship of anticitrullinated peptide autoantibodies to time to rheumatoid arthritis onset

The association between each ACPA and RA varied significantly by time from blood draw to onset $(P<0.0001$ for interaction with time in Cox proportional hazards model). Therefore, we examined the associations among pre-RA subgroups stratified by time to onset within three time windows (less than 5 years, 5 years to less than 10 years and 10 years or longer). The highest reactivity for each ACPA was observed in the subgroup within the time interval closest to onset (Figure 1). Any ACPA-positive was associated with an almost 18-fold increased risk for the subgroup within 5 years of onset $(\mathrm{RR}=17.6(95 \% \mathrm{CI}=$ 5.8 to 53.7)) and a 4-fold increased risk for the subgroup with blood draws 5 to 10 years before onset $(R R=4.2$ $(95 \% \mathrm{CI}=1.7$ to 10.4$)$ ). There was no statistically significant increased risk in the subgroup with blood draws 10 years or more before $\mathrm{RA}$ onset $(\mathrm{RR}=1.4(95 \% \mathrm{CI}=0.5$ to 4.3)) (Figure 1).

Among cases, the number of positive ACPAs was higher the closer the blood draw was to onset. Cases with RA onset sooner after blood draw showed, on average, more reactivity to more ACPAs (Figure 2). We observed a similar trend in higher anti-CCP titers the closer to onset. The number of specific positive ACPAs by time period in cases and controls is listed in Additional file 2: Table S2. When we examined fibrinogen alone, for which we tested seven separate citrullinated peptide reactivities, we found that the number of citrullinated fibrinogen antibodies was higher in those cases with blood draw closer to onset (Figure 3$)\left(P=0.003\right.$ by $\chi^{2}$ test for trend).

When cases were restricted to those diagnosed within 5 years of blood draw, the sensitivity of an ACPA-positive test was $42.2 \%$ and the specificity was $93.3 \%$. In comparison, anti-CCP-positive sensitivity was $26.6 \%$ and the specificity was $100 \%$. Characteristics of the RA cases diagnosed within 5 years of blood draw are described in Additional file 3: Table S3.

\section{Relationship between anticitrullinated peptide autoantibody and HLA-SE}

The HLA-SE-positive/ACPA-positive group carried the highest risk of RA. Comparing those who were HLA$S E$-positive and ACPA-positive to those who were negative for both, the overall OR was 10.4 (95\% CI $=4.3$ to 25.2). When we compared just those with blood draws less than 5 years before RA onset, the OR was 33.3 (95\% $\mathrm{CI}=11.1$ to 99.6 ) (Table 3 ). There was a positive but not statistically significant interaction for the additive scale, suggesting the presence of excess risk from interaction between ACPA and HLA-SE relative to the risk from ACPA and HLA-SE without interaction $(\mathrm{S}=4.5$ (95\% CI $=0.9$ to 24.5$) ; P=0.06$ ). RA patients who were $H L A-S E$ positive showed reactivity to more ACPA types than those who were $H L A-S E$-negative $\left(P=0.01\right.$ by $\chi^{2}$ test for trend) (Figure 4). Only 1 of $23 H L A-S E$-negative cases had five or more positive ACPAs, whereas 15 of 40 $H L A-S E$-positive cases were positive for five or more ACPAs. We further examined the association between $H L A-S E$ and each ACPA using logistic regression models for cases only. We found that antibodies to citrullinated clusterin and vimentin were associated with $H L A-S E$ in patients diagnosed within any time period after blood draw. HLA-SE was associated with citrullinated fibrinogen only within the time interval closest to onset $(P<0.05)$.

Table 2 Anticitrullinated peptide autoantibodies in women and risk of future rheumatoid arthritis in the Nurses' Health Study and the Nurses' Health Study II $^{\mathrm{a}}$

\begin{tabular}{lcccccc}
\hline ACPA target & Positive cases $(\boldsymbol{N}=\mathbf{1 9 2})$ & Positive controls $(\boldsymbol{N}=\mathbf{5 6 7})$ & Unadjusted RR $(\mathbf{9 5} \% \mathbf{C l})$ & $\boldsymbol{P}$ value & Adjusted RR (95\% Cl) & $\boldsymbol{P}$ value \\
\hline Any ACPA & 48 & 38 & $4.9(3.0$ to 7.8$)$ & $<0.0001$ & $4.9(2.9$ to 8.2$)$ & $<0.0001$ \\
Biglycan & 10 & 5 & $6.0(2.1$ to 17.5$)$ & 0.001 & $4.7(1.6$ to 14.2$)$ & 0.006 \\
Clusterin & 25 & 7 & $12.2(5.0$ to 29.8$)$ & $<0.0001$ & $11.7(4.7$ to 26.3$)$ & $<0.0001$ \\
Enolase & 5 & 3 & $5.0(1.2$ to 20.9$)$ & 0.03 & $5.8(1.3$ to 27.1$)$ & 0.02 \\
Fibrinogen & 37 & 22 & $6.3(3.5$ to 11.4$)$ & $<0.0001$ & $5.9(3.2$ to 11.0$)$ & $<0.0001$ \\
Histone 2A & 13 & 8 & $4.9(2.0$ to 11.8$)$ & $<0.001$ & $5.3(2.1$ to 13.2$)$ & $<0.001$ \\
Histone $2 B$ & 18 & 8 & $7.3(3.1$ to 17.6$)$ & $<0.0001$ & $7.0(2.8$ to 17.2$)$ & $<0.0001$ \\
Vimentin & 28 & 11 & $9.8(4.5$ to 21.6$)$ & $<0.0001$ & $9.7(4.3$ to 21.8$)$ & $<0.0001$
\end{tabular}

${ }^{a}$ ACPA: anticitrullinated peptide autoantibody, Cl: confidence interval, RR, risk ratio. RR and $95 \% \mathrm{Cl}$ were estimated by using conditional logistic regression models including matching factors and further adjusted for age at blood draw, alcohol intake, body mass index, regularity of menses and pack-years of smoking. 


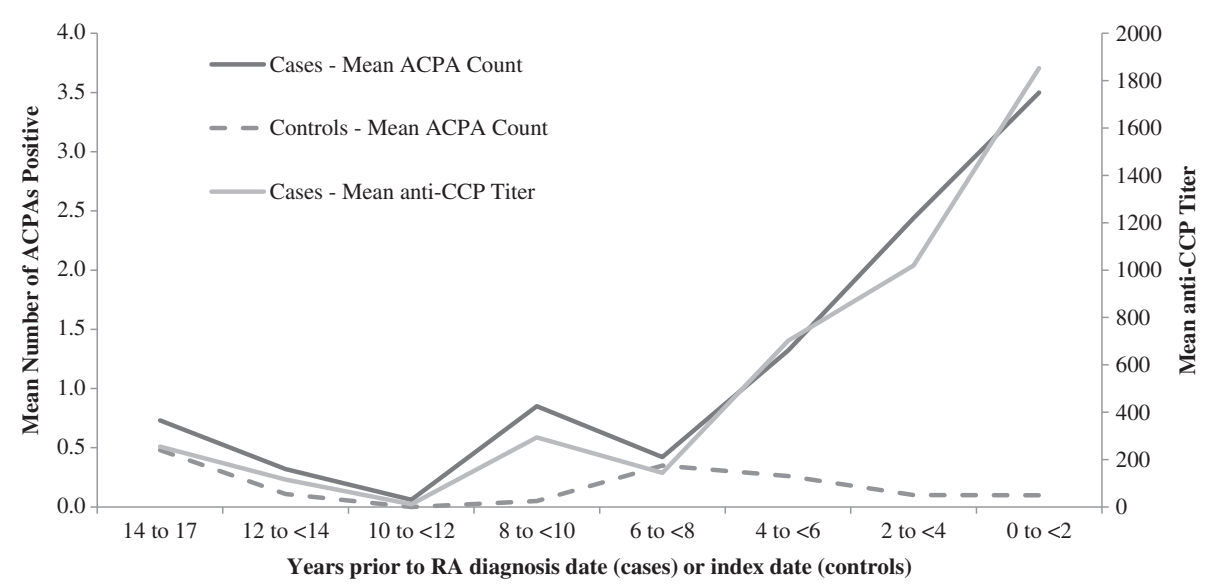

Figure 1 Mean anticitrullinated peptide antibody count and anticyclic citrullinated peptide titer by years prior to rheumatoid arthritis diagnosis. Mean number of positive anticitrullinated peptide antibodies (ACPAs) and anticyclic citrullinated peptide (anti-CCP) titer by time between blood draw and rheumatoid arthritis (RA) diagnosis date in cases and index date in controls in the Nurses' Health Study (NHS) and the Nurses' Health Study II (NHSII). ELISA: enzyme-linked immunosorbent assay.

\section{Discussion}

In this large, prospective cohort study of women followed for many years, we have demonstrated that the majority of a panel of 18 different ACPAs targeted to epitopes in the rheumatoid synovium are strongly associated with risk of future RA. The highest reactivity for each of these ACPAs was observed in the subgroup within 5 years of RA symptom onset. Having any ACPA reactivity was associated with an almost 18-fold increased risk of RA among the subgroup within 5 years of RA symptom onset and a 4fold increased risk within the subgroup with blood draws 5 to 10 years before RA symptom onset. The higher number of ACPAs and the higher overall ACPA reactivity closer to the time of RA onset may be indicative of epitope spreading, as has been reported in prior studies $[5,6,9,10]$. We also found that HLA-SE-positive RA cases showed reactivity to more ACPA subtypes than $H L A$-SE-negative cases and that antibodies to citrullinated clusterin and vimentin were most strongly associated with $H L A-S E$-positive RA.

Three recent case-control studies have identified individuals with stored blood who later developed RA. A blood donor study in the Netherlands examined five ACPAs in seventy-nine donors who gave blood multiple times before they developed RA [5]. Another study analyzed 17 ACPAs using a multiplex panel similar to the panels used in our study in stored serum samples from the US Department of Defense Serum Repository, including 81 individuals who

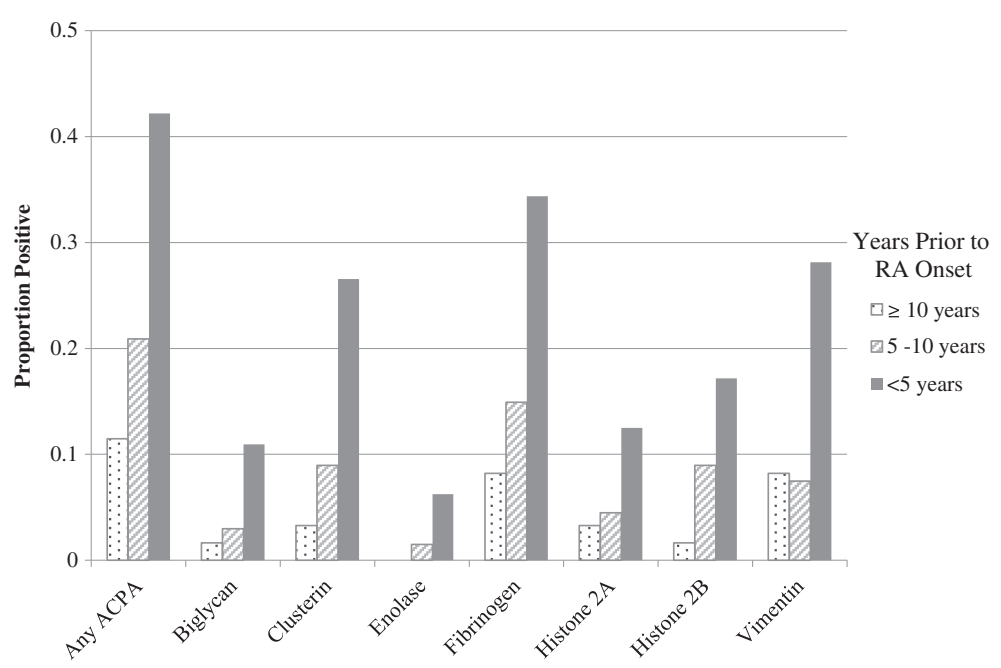

Figure 2 Proportion anticitrullinated peptide antibody-positive cases in pre-rheumatoid arthritis cases by years prior to rheumatoid arthritis diagnosis. Proportion of positive cases for any anticitrullinated peptide antibody (ACPA) and peptide-specific ACPAs in pre-rheumatoid arthritis (RA) cases with blood drawn 10 or more years $(n=61), 5$ years to less than 10 years $(n=67)$ and less than 5 years before diagnosis $(n=64)$ in the Nurses' Health Study and Nurses' Health Study II. Cl: confidence interval, RR: risk ratio. 


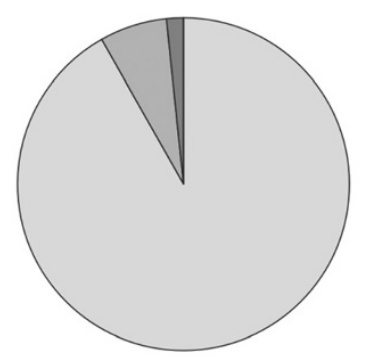

a) $\geq 10$ years

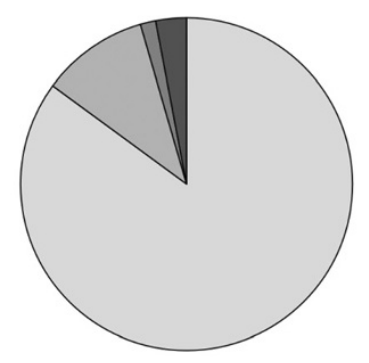

b) 5 - 10 years

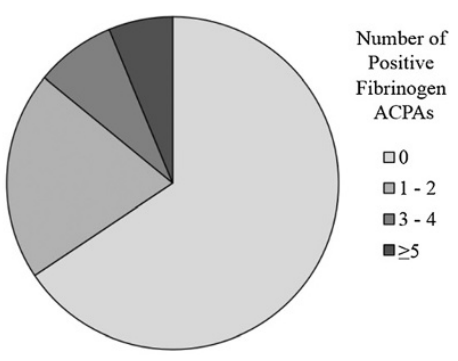

c) $<5$ years

Years Prior to RA Onset

Figure 3 Number of anticitrullinated fibrinogen antibodies in pre-rheumatoid arthritis cases by years prior to rheumatoid arthritis diagnosis. Number of anticitrullinated fibrinogen antibodies in subgroups of cases diagnosed (a) 10 years or more (b) 5 years to less than 10 years and (c) less than 5 years before diagnosis of rheumatoid arthritis (RA) in the Nurses' Health Study and Nurses' Health Study II. ACPA: anticitrullinated peptide antibody.

had blood samples taken before RA diagnosis [6]. A third study examined 10 ACPAs in 374 individuals who had donated blood in Sweden before RA diagnosis [10]. (A subset of these cases was reported by van der Woude et al. [9]). These pre-RA studies also showed increased ACPA reactivity in time periods closest to disease diagnosis and an expansion of the ACPA repertoire over time among cases. Our results are not directly comparable to those from the Netherlands and Sweden, as we used a different panel of ACPAs. However, we employed the same panel of ACPAs tested in the prior US study [6] and found that all peptidespecific ACPAs were associated with a fivefold or greater increased risk of RA.

None of the blood bank studies cited above examined the combined effect of ACPA positivity and HLA-SE on RA risk, however, nor were the investigators able to adjust for potential confounders such as smoking. In the current study, the presence of HLA-SE and any ACPA together conferred an increased risk of RA: a 10-fold increased risk overall and a 33-fold increased risk within 5 years of RA onset. This particular group of individuals is at an especially high risk of imminent RA.

One previous case-control study of pre-RA cases from a Swedish blood donor bank compared those with HLA-SE alleles and commercial anti-CCP assay positivity to those with neither and calculated an OR for $\mathrm{RA}$ of $66.8(95 \% \mathrm{CI}=8.3$ to 549.4$)$ [15]. Researchers in previous studies that included patients with established RA or early RA symptoms have found that the combination of a positive anti-CCP test measured close to the time of diagnosis of RA or individual ACPAs and HLA-SE was greater than the effect of each alone [14,16,33]. However, these findings address a different question: whether ACPAs and HLA-SE are predictive of RA among patients who already have symptoms.

Table 3 Odds ratios for rheumatoid arthritis by anticitrullinated peptide autoantibody positivity and presence of HLA-SE

\begin{tabular}{|c|c|c|c|c|c|c|c|}
\hline \multirow[b]{2}{*}{ Parameter } & \multicolumn{3}{|c|}{ ACPA-negative } & \multicolumn{3}{|c|}{ ACPA-positive } & \multirow[b]{2}{*}{$\begin{array}{l}\text { OR }(95 \% \mathrm{Cl}) \text { for ACPA } \\
\text { within strata of } H L A-S E\end{array}$} \\
\hline & $\begin{array}{l}\text { Cases } \\
(N=36)\end{array}$ & $\begin{array}{l}\text { Controls } \\
(N=268)\end{array}$ & OR $(95 \% \mathrm{Cl})$ & $\begin{array}{l}\text { Cases } \\
(N=27)\end{array}$ & $\begin{array}{l}\text { Controls } \\
(N=15)\end{array}$ & OR $(95 \% \mathrm{Cl})$ & \\
\hline \multirow[t]{2}{*}{ HLA-SE absent } & 17 & 153 & 1.0 (ref) & 6 & 8 & $7.7(2.2$ to 27.5$)$ & $7.7(2.2$ to 27.5$)$ \\
\hline & & & & & & $P=0.002$ & $P=0.002$ \\
\hline \multirow[t]{2}{*}{ HLA-SE present } & 19 & 115 & $1.4(0.7$ to 2.9$)$ & 21 & 7 & 33.3 (11.1 to 99.6$)$ & 23.8 (7.9 to 71.8$)$ \\
\hline & & & $P=0.38$ & & & $P<0.0001$ & $P<0.0001$ \\
\hline OR $(95 \% \mathrm{Cl})$ for HLA-SE present & & & $1.4(0.7$ to 2.9$)$ & & & $4.3(1.0$ to 18.6$)$ & \\
\hline within strata of ACPA & & & $P=0.38$ & & & $P=0.05$ & \\
\hline
\end{tabular}

aCPA: anticitrullinated antibody, Cl: confidence interval, HLA-SE: human leukocyte antigen shared epitope, OR, odds ratio, ref: reference value. Measure of effect modification on the additive scale: Synergy Index $=4.5(95 \% \mathrm{Cl}=0.9$ to $21.6 ; P=0.06)$. Measure of effect modification on the multiplicative scale: ratio of odds ratios $=3.1(95 \% \mathrm{Cl}=0.6$ to $15.8 ; P=0.18)$. ORs estimated by logistic regression models adjusted for matching factors and age at blood draw, alcohol intake, body mass index, regularity of menses and pack-years of smoking. Restricted to cases with blood draw less than 5 years before diagnosis (cases $=63$, controls $=283$ ) in the Nurses' Health Study and Nurses' Health Study II. 

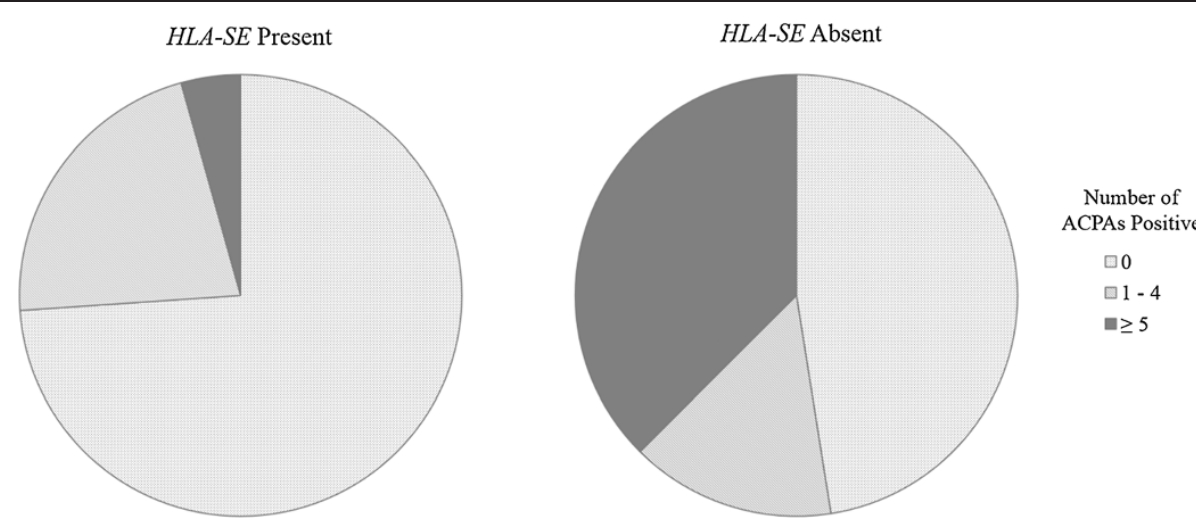

Figure 4 Number of anticitrullinated peptide autoantibodies positive by HLA-SE presence in pre-rheumatoid arthritis cases less than $\mathbf{5}$ years before diagnosis. Number of anticitrullinated peptide antibodies (ACPAs) positive in human leukocyte antigen shared epitope (HLA-SE)negative $(n=23)$ and HLA-SE-positive $(n=40)$ cases diagnosed within 5 years of blood draw in the Nurses' Health Study and Nurses' Health Study II. $P=0.01$ by $X^{2}$ test for trend.

Among the NHS participants who later developed RA, those with $H L A-S E$ had a more diverse ACPA repertoire. Hill and colleagues have demonstrated that major histocompatibility complex class II molecules containing the shared epitope had higher affinity for citrullinated peptides in mice and that citrullinated peptide modification activated a CD4+ T-cell response [34]. We observed that $H L A-S E$ was associated with anticitrullinated vimentin and fibrinogen reactivity in particular, which is congruent with reports by van der Woude et al. (vimentin) [9] and van de Stadt et al. (fibrinogen) [8]. We have further demonstrated that HLA-SE was associated with antibodies to citrullinated clusterin. In this study, we have included ACPAs directed toward well-established peptide targets (fibrinogen, vimentin and enolase [35]) as well as newer targets (biglycan, clusterin and histones $2 \mathrm{~A}$ and $2 \mathrm{~B}$ ), all of which have been shown to be associated with RA. The association between 17 different citrullinated peptides (7 different peptide types) and RA risk suggests that the magnitude and diversity of recognition to many different ACPAs is key to understanding the immune response in the preclinical time period [36].

The generalizability of our study may be limited, as we studied the NHS cohorts, which include only women, but it is thought that RA pathogenesis is similar in men and women. We had only one blood sample per individual; therefore, it was not possible to investigate epitope spreading over time in a single individual. With a follow-up after blood draw of up to 17 years (longer follow-up than previous studies of pre-RA), we were able to investigate if there was an early rise in ACPAs more than 10 years prior to RA onset. Our study helps to increase understanding of the diversity of ACPAs before onset using a relatively large sample of pre-RA cases. We included a large, up-to-date ACPA panel, which enabled us to study ACPA count in relation to HLA-SE and RA onset date, which may be more relevant than one ACPA alone in the years leading up to disease onset. This study is also strengthened by the use of data on health and lifestyle factors taken from questionnaires before blood draw, which allowed us to adjust for potential confounders.

\section{Conclusions}

We found that a diverse ACPA repertoire is associated with $H L A-S E$ and is strongest within 5 years of onset of RA. Our study suggests that there is a broader citrullinated epitope recognition profile instead of one ACPA being responsible for inciting disease. The magnitude of the response to ACPAs in combination with the presence of HLA-SE may be most important for determining the risk of disease. In the future, researchers should continue to investigate whether individual environmental factors trigger the development of ACPA reactivity and immune dysregulation in the peripheral blood before RA onset.

\section{Additional files}

Additional file 1: Table S1. Anti-Citrullinated Peptide Autoantibodies in Women and Risk of Future Rheumatoid Arthritis in NHS and NHSII.

Additional file 2: Table S2. Number of positive anti-citrullinated peptide autoantibodies in preclinical RA cases and their matched controls by time prior to RA onset ( $<5$ years, 5-10 years, $\geq 10$ years) NHS and NHSII.

Additional file 3: Table S3. Characteristics of preclinical RA cases with blood drawn less than 5 years before diagnosis $(\mathrm{N}=64)$ in NHS and NHSII.

\section{Abbreviations}

ACPA: Anticitrullinated peptide autoantibody; ACR: American College of Rheumatology; anti-CCP: Anticyclic citrullinated peptide; BMI: Body mass index; Cl: Confidence interval; HLA-SE: Human leukocyte antigen shared epitope; NHS: Nurses' Health Study; OR: Odds ratio; RA: Rheumatoid arthritis; ROR: Ratio of odds ratio; RR: Risk ratio; S: Synergy index.

\section{Competing interests}

The authors declare that they have no competing interests. 


\section{Authors' contributions}

EVA, BLG, SM, BR, FG, EWK and KHC contributed to the study conception and design. SM helped with data management. EVA performed the analysis. EVA, $\mathrm{BR}, \mathrm{FG}, \mathrm{EWK}$ and $\mathrm{KHC}$ interpreted the results and drafted the paper. JS, WR and CAW performed the laboratory analysis. All authors contributed to editing the draft for content and approved the final version of the paper.

\section{Acknowledgements}

The authors would like to thank the staff and participants of the Nurses Health Studies. This work was supported by the National Institutes of Health (grants AR59073 (to KHC), CA87969, CA49449, CA50385, CA67262, AR49880 and AR52403 (to EWK)) and by a doctoral dissertation award from the Arthritis Foundation (to EVK)

\section{Author details}

'Division of Rheumatology, Immunology and Allergy, Department of Medicine, Brigham and Women's Hospital, Harvard Medical School, 75 Francis Street, Boston, MA 02115, USA. ${ }^{2}$ Department of Epidemiology, Harvard School of Public Health, 677 Huntington Avenue, Boston, MA 02115, USA. ${ }^{3}$ Division of Immunology and Rheumatology, Department of Medicine, Stanford University School of Medicine CCSR, 269 Campus Drive, Stanford, CA 94305, USA. ${ }^{4}$ Department of Biostatistics, Harvard School of Public Health, 677 Huntington Avenue, Boston, MA 02115, USA. ${ }^{5}$ Channing Division of Network Medicine, Department of Medicine, Brigham and Women's Hospital, Harvard Medical School, 181 Longwood Avenue, Boston, MA 02115, USA.

Received: 3 April 2013 Accepted: 2 October 2013

Published: 23 October 2013

\section{References}

1. Whiting PF, Smidt N, Sterne JA, Harbord R, Burton A, Burke M, Beynon R, Ben-Shlomo Y, Axford J, Dieppe P: Systematic review: accuracy of anticitrullinated peptide antibodies for diagnosing rheumatoid arthritis. Ann Intern Med 2010, 152:456-464. W155-166.

2. Montes A, Perez-Pampin E, Calaza M, Gomez-Reino JJ, Gonzalez A: Association of anti-citrullinated vimentin and anti-citrullinated a-enolase antibodies with subsets of rheumatoid arthritis. Arthritis Rheum 2012. 64:3102-3110.

3. Lundberg K, Bengtsson C, Kharlamova N, Reed E, Jiang X, Kallberg H, PollakDorocic I, Israelsson L, Kessel C, Padyukov L, Holmdahl R, Alfredsson L, Klareskog L: Genetic and environmental determinants for disease risk in subsets of rheumatoid arthritis defined by the anticitrullinated protein/ peptide antibody fine specificity profile. Ann Rheum Dis 2013, 72:652-658.

4. Snir O, Widhe M, von Spee C, Lindberg J, Padyukov L, Lundberg K Engstrom A, Venables PJ, Lundeberg J, Holmdahl R, Klareskog L, Malmström $\checkmark$ : Multiple antibody reactivities to citrullinated antigens in sera from patients with rheumatoid arthritis: association with HLA-DRB1 alleles. Ann Rheum Dis 2009, 68:736-743.

5. van de Stadt $L A$, de Koning MH, van de Stadt RJ, Wolbink G, Dijkmans BA, Hamann D, van Schaardenburg D: Development of the anti-citrullinated protein antibody repertoire prior to the onset of rheumatoid arthritis. Arthritis Rheum 2011, 63:3226-3233.

6. Sokolove J, Bromberg R, Deane KD, Lahey LJ, Derber LA, Chandra PE, Edison JD, Gilliland WR, Tibshirani RJ, Norris JM, Holers VM, Robinson WH: Autoantibody epitope spreading in the pre-clinical phase predicts progression to rheumatoid arthritis. PLoS One 2012, 7:e35296.

7. Aggarwal R, Liao K, Nair R, Ringold S, Costenbader KH: Anti-citrullinated peptide antibody assays and their role in the diagnosis of rheumatoid arthritis. Arthritis Rheum 2009, 61:1472-1483.

8. van de Stadt LA, van der Horst AR, de Koning MH, Bos WH, Wolbink GJ, van de Stadt RJ, Pruijn GJ, Dijkmans BA, van Schaardenburg D, Hamann D: The extent of the anti-citrullinated protein antibody repertoire is associated with arthritis development in patients with seropositive arthralgia. Ann Rheum Dis 2011, 70:128-133.

9. van der Woude D, Rantapää-Dahlqvist S, loan-Facsinay A, Onnekink C, Schwarte CM, Verpoort KN, Drijfhout JW, Huizinga TW, Toes RE, Pruijn GJ: Epitope spreading of the anti-citrullinated protein antibody response occurs before disease onset and is associated with the disease course of early arthritis. Ann Rheum Dis 2010, 69:1554-1561.

10. Brink M, Hansson M, Mathsson L, Jakobsson PJ, Holmdahl R, Hallmans G, Stenlund H, Rönnelid J, Klareskog L, Rantapää-Dahlqvist S: Multiplex analyses of antibodies against citrullinated peptides in individuals prior to development of rheumatoid arthritis. Arthritis Rheum 2013, 65:899-910

11. Fernando MM, Stevens CR, Walsh EC, De Jager PL, Goyette P, Plenge RM, Vyse TJ, Rioux JD: Defining the role of the MHC in autoimmunity: a review and pooled analysis. PLoS Genet 2008, 4:e1000024.

12. Jawaheer D, Li W, Graham RR, Chen W, Damle A, Xiao X, Monteiro J, Khalil H, Lee A, Lundsten R, Begovich A, Bugawan T, Erlich H, Elder JT, Criswell LA, Seldin MF, Amos Cl, Behrens TW, Gregersen PK: Dissecting the genetic complexity of the association between human leukocyte antigens and rheumatoid arthritis. Am J Hum Genet 2002, 71:585-594.

13. Gregersen PK, Silver J, Winchester RJ: The shared epitope hypothesis: an approach to understanding the molecular genetics of susceptibility to rheumatoid arthritis. Arthritis Rheum 1987, 30:1205-1213.

14. Mahdi H, Fisher BA, Kallberg H, Plant D, Malmstrom V, Ronnelid J, Charles P, Ding B, Alfredsson L, Padyukov L, Symmons DP, Venables PJ, Klareskog L, Lundberg $K$ : Specific interaction between genotype, smoking and autoimmunity to citrullinated a-enolase in the etiology of rheumatoid arthritis. Nat Genet 2009, 41:1319-1324.

15. Berglin E, Padyukov L, Sundin U, Hallmans G, Stenlund H, van Venrooij WJ, Klareskog L, Dahlqvist SR: A combination of autoantibodies to cyclic citrullinated peptide (CCP) and HLA-DRB1 locus antigens is strongly associated with future onset of rheumatoid arthritis. Arthritis Res Ther 2004, 6:R303-R308.

16. Balsa A, Cabezón A, Orozco G, Cobo T, Miranda-Carus E, López-Nevot MA, Vicario JL, Martín-Mola E, Martín J, Pascual-Salcedo D: Influence of HLA DRB1 alleles in the susceptibility of rheumatoid arthritis and the regulation of antibodies against citrullinated proteins and rheumatoid factor. Arthritis Res Ther 2010, 12:R62

17. Karlson EW, Chibnik LB, Cui J, Plenge RM, Glass RJ, Maher NE, Parker A, Roubenoff R, Izmailova E, Coblyn JS, Weinblatt ME, Shadick NA: Associations between human leukocyte antigen, PTPN22, CTLA4 genotypes and rheumatoid arthritis phenotypes of autoantibody status, age at diagnosis and erosions in a large cohort study. Ann Rheum Dis 2008, 67:358-363.

18. Verpoort KN, Cheung K, loan-Facsinay A, van der Helm-van Mil AH, de VriesBouwstra JK, Allaart CF, Driifhout JW, de Vries RR, Breedveld FC, Huizinga TW, Pruijn GJ, Toes RE: Fine specificity of the anti-citrullinated protein antibody response is influenced by the shared epitope alleles. Arthritis Rheum 2007, 56:3949-3952.

19. Lee HS, Irigoyen P, Kern M, Lee A, Batliwalla F, Khalili H, Wolfe F, Lum RF, Massarotti E, Weisman M, Bombardier C, Karlson EW, Criswell LA, Vlietinck R, Gregersen PK: Interaction between smoking, the shared epitope, and anticyclic citrullinated peptide: a mixed picture in three large North American rheumatoid arthritis cohorts. Arthritis Rheum 2007, 56:1745-1753.

20. van der Helm-van Mil AH, Verpoort KN, le Cessie S, Huizinga TW, de Vries RR, Toes RE: The HLA-DRB1 shared epitope alleles differ in the interaction with smoking and predisposition to antibodies to cyclic citrullinated peptide. Arthritis Rheum 2007, 56:425-432.

21. Klareskog L, Stolt P, Lundberg K, Källberg H, Bengtsson C, Grunewald J, Rönnelid J, Harris HE, Ulfgren AK, Rantapää-Dahlqvist S, Eklund A, Padyukov L, Alfredsson L: A new model for an etiology of rheumatoid arthritis: smoking may trigger HLA-DR (shared epitope)-restricted immune reactions to autoantigens modified by citrullination. Arthritis Rheum 2006, 54:38-46.

22. Karlson EW, Mandl LA, Hankinson SE, Grodstein F: Do breast-feeding and other reproductive factors influence future risk of rheumatoid arthritis? Results from the Nurses' Health Study. Arthritis Rheum 2004, 50:34583467.

23. Karlson EW, Chibnik LB, Tworoger SS, Lee IM, Buring JE, Shadick NA, Manson $\mathrm{JE}$, Costenbader $\mathrm{KH}$ : Biomarkers of inflammation and development of rheumatoid arthritis in women from two prospective cohort studies. Arthritis Rheum 2009, 60:641-652.

24. Karlson EW, Sanchez-Guerrero J, Wright EA, Lew RA, Daltroy LH, Katz JN, Liang MH: A connective tissue disease screening questionnaire for population studies. Ann Epidemiol 1995, 5:297-302.

25. Arnett FC, Edworthy SM, Bloch DA, McShane DJ, Fries JF, Cooper NS, Healey LA, Kaplan SR, Liang MH, Luthra HS, Medsger TA Jr, Mitchell DM, Neustadt DH, Pinals RS, Schaller JG, Sharp JT, Wilder RL, Hunder GG: The American Rheumatism Association 1987 revised criteria for the classification of rheumatoid arthritis. Arthritis Rheum 1988, 31:315-324.

26. Monach PA, Hueber W, Kessler B, Tomooka BH, BenBarak M, Simmons BP, Wright J, Thornhill TS, Monestier M, Ploegh H, Robinson WH, Mathis D, 
Benoist C: A broad screen for targets of immune complexes decorating arthritic joints highlights deposition of nucleosomes in rheumatoid arthritis. Proc Natl Acad Sci USA 2009, 106:15867-15872.

27. Costenbader KH, Feskanich D, Mandl LA, Karlson EW: Smoking intensity, duration, and cessation, and the risk of rheumatoid arthritis in women. Am J Med 2006, 119:503. e1-503.e9.

28. Pedersen M, Jacobsen $S$, Klarlund M, Pedersen BV, Wiik A, Wohlfahrt J, Frisch M: Environmental risk factors differ between rheumatoid arthritis with and without auto-antibodies against cyclic citrullinated peptides. Arthritis Res Ther 2006, 8:R133.

29. Källberg H, Ding B, Padyukov L, Bengtsson C, Rönnelid J, Klareskog L, Alfredsson L, EIRA Study Group: Smoking is a major preventable risk factor for rheumatoid arthritis: estimations of risks after various exposures to cigarette smoke. Ann Rheum Dis 2011, 70:508-511.

30. Källberg H, Jacobsen S, Bengtsson C, Pedersen M, Padyukov L, Garred P, Frisch M, Karlson EW, Klareskog L, Alfredsson L: Alcohol consumption is associated with decreased risk of rheumatoid arthritis: results from two Scandinavian case-control studies. Ann Rheum Dis 2009, 68:222-227.

31. Wesley A, Bengtsson C, Elkan AC, Klareskog L, Alfredsson L, Wedrén S, Epidemiological Investigation of Rheumatoid Arthritis Study Group: Association between body mass index and anti-citrullinated protein antibody-positive and anti-citrullinated protein antibody-negative rheumatoid arthritis: results from a population-based case-control study. Arthritis Care Res (Hoboken) 2013, 65:107-112.

32. Hosmer DW, Lemeshow S: Confidence interval estimation of interaction. Epidemiology 1992, 3:452-456.

33. van der Helm-van Mil AH, Verpoort KN, Breedveld FC, Huizinga TW, Toes RE, de Vries RR: The HLA-DRB1 shared epitope alleles are primarily a risk factor for anti-cyclic citrullinated peptide antibodies and are not an independent risk factor for development of rheumatoid arthritis. Arthritis Rheum 2006, 54:1117-1121.

34. Hill JA, Southwood S, Sette A, Jevnikar AM, Bell DA, Cairns E: Cutting edge: the conversion of arginine to citrulline allows for a high-affinity peptide interaction with the rheumatoid arthritis-associated HLA-DRB1*0401 MHC class II molecule. J Immunol 2003, 171:538-541.

35. Wegner N, Lundberg K, Kinloch A, Fisher B, Malmström V, Feldmann M, Venables PJ: Autoimmunity to specific citrullinated proteins gives the first clues to the etiology of rheumatoid arthritis. Immunol Rev 2010, 233:34-54.

36. van der Woude D, Alemayehu WG, Verduijn W, de Vries RR, HouwingDuistermaat JJ, Huizinga TW, Toes RE: Gene-environment interaction influences the reactivity of autoantibodies to citrullinated antigens in rheumatoid arthritis. Nat Genet 2010, 42:814-816.

\section{doi:10.1186/ar4342}

Cite this article as: Arkema et al:: Anti-citrullinated peptide

autoantibodies, human leukocyte antigen shared epitope and risk of future rheumatoid arthritis: a nested case-control study. Arthritis

Research \& Therapy 2013 15:R159.

\section{Submit your next manuscript to BioMed Central and take full advantage of:}

- Convenient online submission

- Thorough peer review

- No space constraints or color figure charges

- Immediate publication on acceptance

- Inclusion in PubMed, CAS, Scopus and Google Scholar

- Research which is freely available for redistribution 